\title{
THE INFLUENCE OF ACID ETCHING OR CHITOSAN DENTIN SURFACE TREATMENTS ON DENTIN WETTABILITY AND SHEAR BOND STRENGTH OF SELF- ETCH ADHESIVES
}

\author{
Dalia A. Abuelenain*
}

\begin{abstract}
The aim of the study was to investigate the influence of dentin surface preparation with acid etching or chitosan treatment on dentin wettability and shear bond strength to resin composite using self-etch adhesive.

Methods: Fifteen human sound extracted third molars were used in the study. Dentin disks were cut from the crown for evaluation of dentin wettability, and the remaining part of the crown was used for the shear test. Dentin discs were divided randomly into 3 groups $(n=5)$ treated as follow: G1: control, G2: acid etched with $32 \%$ phosphoric acid, and G3: treated with Chitosan for $60 \mathrm{~s}$. Contact angle of treated dentin surfaces with a self-etch single bond universal adhesive was measured using a drop shape analyzer. The remaining crowns used for shear bond strength test (SBS) were divided randomly into three groups $(n=5)$ and prepared in the same manner used for wetting evaluation. Nano-hybrid composite material were bonded to treated dentin surface using self-etch adhesive. Samples were subjected to SBS testing in a universal testing machine.
\end{abstract}

Results obtained, showed statistically significant lower contact angle after chitosan treatment of dentin surfaces as compared to control and acid etched groups $(\mathrm{p}<0.05)$. On the other hand, both acid etching and chitosan treatment of dentin surfaces resulted in a statistically significant lower SBS compared to control untreated group $(\mathrm{p}<0.05)$.

Conclusion: Bonding to dentin using self-etch adhesive is best achieved with direct application of adhesive resin on untreated dentin surface.

KEY WORDS: Chitosan, shear bond, adhesives, dentin, self-etch.

\section{INTRODUCTION}

Bonding dental esthetic restorations to dentin using self-etch adhesives has gain popularity in recent years due to the advantages of self-etch systems such as being less technique sensitive compared to other dentin bonding systems (1), prevents the collapse of air-dried dementalized collagen fibers as the smear layer within the dentin

* King Abdulaziz University Faculty of Dentistry, Operative Dentistry Department, Biomaterials Division, Jeddah, Saudi Arabia. 
surface is demineralized and polymerized in situ, and a good seal obtained as the smear plug is not removed ${ }^{(1,2)}$. However, recurrent decay is still the main cause of composite restoration failure ${ }^{(3)}$ and the need to reduce bacterial evolution at the restoration surface and at the tooth- restoration interphase is crucial.

Successful bonding of dental adhesives to tooth substrate is influenced by two main factors: wetting of dentin surface by the adhesive resin and the proper impregnation of dentin substrate by the adhesive resin ${ }^{(4-6)}$. Evaluation of dentin wettability can be achieved by measuring the contact angle of a drop of the adhesive resin on prepared dentin surface, in which the value of the contact angle is mostly influenced by dentin surface roughness, surface tension of dentin and adhesive, chemical surface properties of dentin and by the surface hydration state ${ }^{(5)}$. The influence of dentin wettability on improving adhesive bond efficiency and reduction of microleakage was proved in total-etch bonding technique ${ }^{(6)}$, however, a controversial issues were raised in self-etch adhesives ${ }^{(7,8)}$.

Self-etch adhesives are applied to dentin surface either without any dentin surface preparation relying on the action of acidic monomer on hydroxyapatite of dentinal tubules (2), or applied to a wet acid etched dentin surface after removal of smear layer to provide further micromechanical interlocking in addition to the chemical bonding ${ }^{(2,5,9)}$. In such case an increased bond integrity between self-etch adhesive and etched dentin surface is anticipated, when compared to the bond integrity between selfetch adhesive and un-etched dentin surface

However, several studies showed that acid etching of dentin surface before the application of self-etch adhesives may reduce the bond strength between the resin material and acid etched dentin ${ }^{(7,8)}$ and this area remains an area of scientific interest.

Chitosan is a natural and biocompatible polymer with a broad range of antibacterial and antibiofilm activity ${ }^{(10)}$. In addition, chitosan can form a micro and nano-fibbillar network and in several previous engineering researches, chitosan proved to be able to reinforce the collagen scaffolds ${ }^{(10)}$.

Therefore, the use of self-etch adhesive in combination with chitosan may provide the dual effect of reinforcing the collagen network in the hybrid layer hence the integrity of the resin-dentin interphase as well as developing antibacterial zone at the restoration-dentin interphase, which may influence the durability of the adhesive bond by lowering the incidence of recurrent decay ${ }^{(11)}$.

Shear bond strength (SBS) is a mechanical test of the adhesive interphase that can provide an indication of the bond integrity between esthetic restorations and dentin surface. Reliable results were achieved in previous researches studying dentin-adhesives interphase ${ }^{(12-19)}$.

Therefore, the aim of the present study is to investigate the influence of dentin treatment with acid etching or chitosan application on dentin wettability and shear bond strength to composite resins using self-etch adhesives.

Null hypothesis: Acid etching or chitosan surface treatment of dentin prior to self-etch adhesive application will not influence dentin wettability and shear bond strength to composite resin when using self-etch adhesive resins.

\section{MATERIALS AND METHOD}

Details of the material used in the study are presented in table 1 .

\section{Sample preparation:}

Fifteen human sound extracted third molars were collected from King Abdulaziz University hospital dental clinics with the informed consent of the donors. Occlusal enamel and superficial dentin were removed using a low speed diamond saw with water irrigation (Micromet AG, Munich, Germany). 
Dentin disks (1mm thick) were cut from the crown to be used for evaluation of dentin wettability, and the remaining part of the crown was used for the shear bond strength test (Figure 1).

\section{Dentin wettability evaluation:}

Dentin discs were used to evaluate the contact angle of treated dentin with Single bond universal adhesive (3M ESPE). Fifteen freshly cut discs were finished with 360 grit silicon carbide papers at the top surface to create a standardized smear layer and to provide flat and smooth surfaces, then divided randomly into three groups $(n=5)$.
Group I (control); no treatment was applied to dentin surface, Group II: dentin discs were acid etched with $32 \%$ phosphoric acid for $15 \mathrm{~s}$, then rinsed with water and blot-dried with a minisponge, Group III: Dentin discs were treated with chitosan prepared as follows $0.1 \mathrm{~mol} / \mathrm{L}$ acetic acid (HAc) (1.14ml Glacial HAc to $199 \mathrm{ml}$ of water)] and applied for $60 \mathrm{~s}$ on dentin surface, then dried with gentle stream of air.

A drop of Single bond universal adhesive was applied to each dentin disc and the contact angles was determined using a drop shape analyzer (Kruss) to determine the wettability of dentin with the selfetch adhesive after different dentin treatments.

TABLE (1) Chemical composition and manufacturer of materials used in the study.

\begin{tabular}{|l|l|l|}
\hline \multicolumn{1}{|c|}{ Material } & \multicolumn{1}{|c|}{ Manufacturer } & \multicolumn{1}{c|}{ Chemical composition } \\
\hline $\begin{array}{l}\text { Scotchbond universal } \\
\text { etchant }\end{array}$ & $\begin{array}{l}\text { 3M ESPE, St. Paul, } \\
\text { MN, USA }\end{array}$ & $32 \mathrm{wt} \%$ phosphoric acid \\
\hline $\begin{array}{l}\text { Chitosan } \\
\text { Medium molecular weight }\end{array}$ & $\begin{array}{l}\text { ALDRICH } \\
\text { chemistry }\end{array}$ & Deacetylated chitin, Poly(D-glucosamine) \\
\hline $\begin{array}{l}\text { Single bond universal } \\
\text { adhesive }\end{array}$ & $\begin{array}{l}3 \mathrm{M} \text { ESPE, St. Paul, } \\
\text { MN, USA }\end{array}$ & $\begin{array}{l}\text { MDP Phosphate Monomer, Dimethacrylate resins, HEMA, Vitrebond } \\
\text { copolymer, filler, ethanol, water, initiators, Silane }\end{array}$ \\
\hline $\begin{array}{l}\text { Filtek Z350 XT } \\
\text { Composite material }\end{array}$ & $\begin{array}{l}\text { MN ESPE, St. Paul, }, \\
\text { Bis-GMA, UDMA, TEGDMA, and bis-EMA(6), PEGDMA. } \\
\text { Agglomerated/non-aggregated 20 nm silica filler, non-agglomerated/non- } \\
\text { aggregated 4 -11 nm zirconia filler, and aggregated zirconia/silica cluster } \\
\text { filler 20 nm silica and 4 -11 nm zirconia particles }\end{array}$ \\
\hline
\end{tabular}

Abbreviations: MDP: Phenyl-P,10-methacryloyloxydecyl dihydrogen phosphate.

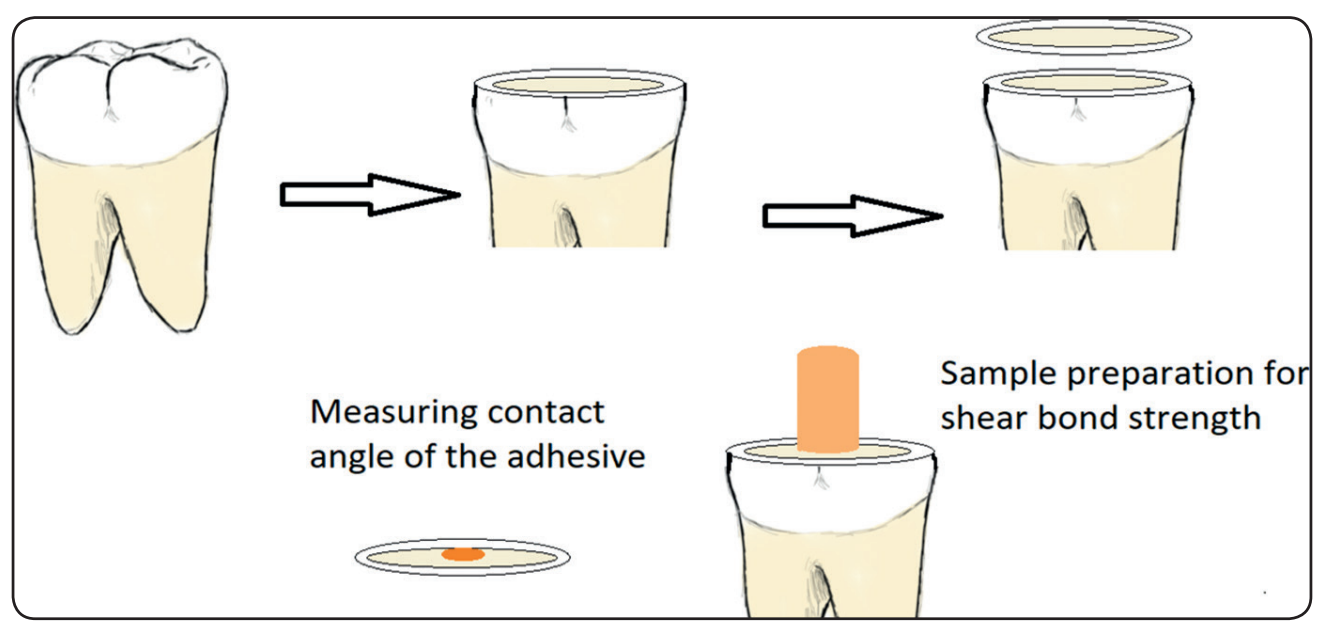

Fig. (1) Schematic illustrations of sample preparation 
TABLE (2) Means and standard deviations (SD) of contact angle and shear bond strength (MPa) of different groups:

\begin{tabular}{|c|c|c|c|}
\hline & Control $(\mathrm{G} 1)$ & Acid etched dentin $(\mathrm{G} 2)$ & Chitosan Treated dentin $(\mathrm{G} 3)$ \\
\hline Mean contact angle & $38^{\mathrm{a}}$ & $38.5^{\mathrm{a}}$ & $33.3^{\mathrm{b}}$ \\
$(\mathrm{SD})$ & $(2)$ & $(3)$ & $3.5)$ \\
\hline Mean shear bond strength & $8.5^{\mathrm{A}}$ & $3^{\mathrm{B}}$ & $3.5^{\mathrm{B}}$ \\
$(\mathrm{SD})$ & $(1.5)$ & $(1.6)$ & $(1)$ \\
\hline
\end{tabular}

Different letters with the same case in the same raw represents significant difference among tested groups at $p=0.05$ level of significance.

\section{Shear bond strength test:}

The remaining part of the crown was used for shear bond strength test. The exposed dentin surface was finished with 360 grit silicon carbide papers.

Prepared teeth were divided randomly into three groups ( $n=5)$, prepared in the same manner used for wettability evaluation explained previously.

Cylindrical Teflon split-mold (4 X 4mm) was used on the top of dentin surface to confine the testing area. Bonding agent was applied to prepared dentin surface at the base of the cylindrical mold, according to manufacturer instructions and light cured with blue light (BL) (light-emitting diode curing unit; 3 M ESPE, Elipar, Seefeld, Germany) delivering $1200 \mathrm{~mW} / \mathrm{cm}^{2}$, at $430-480 \mathrm{~nm}$ for $20 \mathrm{~s}$. Nano-hybrid composite material (Filtek Z350 XT, 3 M ESPE) were added inside the cylinder in two increments. Each increment was light cured with BL for 40 seconds.

Prepared samples in each group were stored in distilled water for 24 hours at $37^{\circ} \mathrm{C}$. Samples were subjected to shear bond testing in a universal testing machine (Instron 5944, USA) at a load rate of $0.5 \mathrm{~mm} / \mathrm{min}$ until failure and the maximum load at fracture was recorded.

Data were collected and subjected to One-way ANOVA and post hoc Tukey's test using SPSS software (Released 2011, IBM SPSS Statistics for
Windows, Version 20.0, IBM Corp., Armonk, New York, USA).

\section{RESULTS}

Mean and standard deviations (SD) of contact angle and shear bond strength in $\mathrm{MPa}$ are presented in table 2.

Statistically significant difference was observed between different groups in regards to contact angle $(\mathrm{p}=0.01)$ and SBS $(\mathrm{p}<0.001)$.

Tukey's post hoc test revealed that chitosan treated dentin surfaces resulted in significantly lower contact angle when compared to control $(\mathrm{p}=0.026)$ and acid etched $(\mathrm{p}=0.014)$ groups .

However, both acid etched and chitosan treated dentin surfaces resulted in a statistically significant lower SBS compared to control group, $(\mathrm{p}<0.0001)$.

\section{DISCUSSION}

With the traditional dentin bonding technique in which a total etch is applied, the dentin wettability increases as a result of acid etching with phosphoric acid ${ }^{(6)}$. This was due to the increased surface energy of dentin and increase water content within dentinal tubules ${ }^{(20)}$. In order for the adhesive material to spread over acid etched dentin, it has to contain hydrophilic component with water-ethanol mix as a solvent. This component was present in the Single 
bond universal adhesive used in the present study as presented in table 1. However, in the present work, acid etching of dentin surface didn't influence the dentin surface wettability, while, chitosan treatment of unetched dentin surface significantly increased dentin wettability. These results require a partial rejection of null hypothesis.

The influence of acid etching on dentin wettability observed in the present work was in accordance with the previous work ${ }^{(5)}$, in which a reduction in dentin wettability by adhesive resin after acid etching was observed and ascribed to two main contributing factors: 1) the presence of small air pockets in the dentinal tubules that may be trapped during air drying process, and 2) acid etching resulting in an increase in surface energy of the inner walls of the tubules, in which it will reduce its local wettability. Therefore, the dentinal tubules will provide a hydrophobic contribution to the dentin surface, which will result in the observed lower wettability of the etched dentin surface ${ }^{(5)}$. This may explain the slight non-significant reduction of dentin wettability after acid etching observed in the present study.

In total -etch technique, previous investigations confirmed the relation between dentin wettability and bond strength at the dentin-resin interphase in addition to reduced leakage ${ }^{\left({ }^{6}\right)}$. This was different in the present study, in which acid etching did not increase wettability of the dentin surface with selfetch adhesive, in spite, there was a reduction in bond strength after dentin etching. While treating the dentin surface with chitosan, increased dentin wettability significantly, but also reduced the bond strength.

This was also observed in a previous work in which the dentin wettability did not correlate with adhesive bond efficiency in self-etch adhesives ${ }^{(4)}$, in contrary to total-etch techniques. This was inferred to the complexity of bonding mechanism in self-etch adhesives and to other factors which may contribute to bond strength in addition to high wetting, such as the primer ionization and solvent evaporation.

The results of the current work showed a significantly higher shear bond strength of resin composite to untreated dentin surface using selfetch adhesive compared to bonding to acid-etched or chitosan treated dentin surfaces. This is in agreement with previous studies in which the acid etching of dentin prior to application of self-etched adhesives resulted in lower shear bond strength ${ }^{(7,8)}$. This was inferred to the dissolution of intrafibrillar and extrafibrillar minerals achieved by acid etching and the incomplete infiltration of the demineralized collagen layer by the resin monomer ${ }^{(8)}$. In addition, the collapse of the unsupported collagen could be responsible for lowering the depth of penetration of resin into decalcified dentin and then lowering bond strength between resin and etched dentin surface.

In spite of the increased wettability of dentin after chitosan application to unetched dentin surface, the shear bond strength of resin composite to chitosan treated dentin surface were lower than bond strength to untreated dentin surface and similar to bond strength to acid etched dentin. As it is stated previously in this paper the dentin wettability may not reflect the bond strength; the present result further confirms this deduction. The lower bond strength to chitosan treated dentin surface could be inferred to the residual traces of chitosan within dentinal tubules that could prevent the adhesive penetration and hence an insufficient support of the collagen network. These assumptions require further microstructural analysis of the resin-dentin interphase. In addition, more trials are required to address an ideal method and technique of treating dentin surface with antimicrobial agents such as chitosan, without jeopardizing the resin-dentin bond integrity. 


\section{CONCLUSION}

Within the limitations of the present study, it can be concluded that, acid etching or chitosan surface treatment of dentin surface prior to application of self-etch adhesives did not positively influenced the bond integrity to resin restorations.

\section{CONFLICT OF INTEREST}

The author declares that there is no conflict of interest regarding the publication of this paper.

\section{REFERENCES}

1. Tay FR, Pashley DH. Aggressiveness of contemporary self-etching systems. I: Depth of penetration beyond dentin smear layers. Dent Mater. 2001;17(4):296-308.

2. Giannini M, Makishi P, Almeida Ayres AP, Moreira Vermelho P, Marin Fronza B, Nikaido T, et al. Selfetch adhesive systems: A literature review. Braz Dent J. 2015;26(1):3-10.

3. Rasines Alcaraz MG, Veitz-Keenan A, Sahrmann P, Schmidlin PR, Davis D, Iheozor-Ejiofor Z. Direct composite resin fillings versus amalgam fillings for permanent or adult posterior teeth. Cochrane Database Syst Rev 2014,. $31 ;(3)$.

4. Aguilar-Mendoza JA, Rosales-Leal JI, Rodríguez-Valverde MA, González-López S, Cabrerizo-Vílchez MA. Wettability and bonding of self-etching dental adhesives. Influence of the smear layer. Dent Mater. 2008;24(7):994 1000 .

5. Farge P, Alderete L, Ramos SMM. Dentin wetting by three adhesive systems: Influence of etching time, temperature and relative humidity. J Dent. 2010;38(9):698-706.

6. Rosales-Leal JI, Osorio R, Holgado-Terriza JA, CabrerizoVílchez MA, Toledano M. Dentin wetting by four adhesive systems. Dent Mater. 2001;17(6):526-32.

7. Ikeda M, Kurokawa H, Sunada N, Tamura Y, Takimoto M, Murayama R, et al. Influence of previous acid etching on dentin bond strength of self-etch adhesives. J Oral Sci. 2009;51(4):527-34.

8. Van Landuyt KL, Kanumilli P, De Munck J, Peumans M, Lambrechts P, Van Meerbeek B. Bond strength of a mild self-etch adhesive with and without prior acid-etching. J Dent. 2006;34(1):77-85.
9. Oliveira SSA, Pugach MK, Hilton JF, Watanabe LG, Marshall SJ, Marshall GW. The influence of the dentin smear layer on adhesion: A self-etching primer vs. a total-etch system. Dent Mater. 2003;19(8):758-67.

10. Fawzy AS, Nitisusanta LI, Iqbal K, Daood U, Beng LT, Neo J. Chitosan/Riboflavin-modified demineralized dentin as a potential substrate for bonding. J Mech Behav Biomed Mater. 2012;17:278-89.

11. Kong M, Chen XG, Xing K, Park HJ. Antimicrobial properties of chitosan and mode of action: A state of the art review. Int J Food Microbiol. 2010;144(1):51-63.

12. Jayasheel A, Niranjan N, Pamidi H, Suryakanth MB. Comparative Evaluation of shear Bond Strength of universal Dental Adhesives -An in vitro study. J Clin Exp Dent. 2017;9(7):892-6.

13. Tang L, Zhang Y, Liu Y, Zhou Y. Influence of EDC on dentin-resin shear bond Strength and demineralized dentin thermal properties. Materials (Basel). 2016;9(11):1-12.

14. Akhondali Z, Dianat M, Radan M. Comparison of the shear bond strength of self-adhesive resin cements to enamel and dentin with different protocol of application. Electron Physician. 2015;7(1):971-6.

15. Koliniotou-Koumpia E, Kouros P, Koumpia E, Helvatzoglou-Antoniades M. Shear bond strength of a "solventfree" adhesive versus contemporary adhesive systems. Brazilian J Oral Sci. 2014;13(1):64-9.

16. Raposo CC, Santana IL. Shear bond strength of self-etch and total-etch adhesives to bovine enamel and dentin\Rev. odonto ciênc. 2012;27(2):143-6.

17. Villela-Rosa ACM, Gonçalves M, Orsi IA, Miani PK. Shear bond strength of self-etch and total-etch bonding systems at different dentin depths. Braz Oral Res. 2011;25(2):109-15.

18. Al Qahtani MQ, Al Shethri SE. Shear bond strength of one-step self-etch adhesives with different co-solvent ingredients to dry or moist dentin. Saudi Dent J. 2010;22(4): 171-5.

19. Rasmussen ST. Analysis of dental shear bond strength tests, shear or tensile? Int J Adhes Adhes. 1996;16(3): 147-54.

20. Moszner N, Salz U, Zimmermann J. Chemical aspects of self-etching enamel-dentin adhesives: A systematic review. Dent Mater. 2005;21(10):895-910. 